\title{
Fish Distribution and Partial Recruitment: The Case of Eastern Scotian Shelf Cod
}

\author{
A. Sinclair \\ Department of Fisheries and Oceans, Gulf Fisheries Center \\ P. O. Box 5030, Moncton, New Brunswick, Canada E1C $9 B 6$
}

\begin{abstract}
The distribution-at-age of cod (Gadus morhua) in NAFO Subdiv. 4Vs and 4W was investigated as part of a study to determine possible mechanisms for differences in partial recruitment (PR) among fishing fleets. The results of research vessel surveys were used to describe fish distribution while the distribution of fishing vessels was described using logbook and observer data. Young fish (ages 1-4) were more abundant on shallow banks in the south and west of the study area and were found at higher temperatures. Older fish (age $5+$ ) were found at progressively greater depths toward the north and east and at colder temperatures. Distributions of cod with depth and temperature differed from the average conditions in the survey area indicating that cod sought areas with specific conditions. Longline fishing effort was concentrated in areas where older fish were more abundant while otter trawl effort was concentrated in areas where middle aged fish were more abundant. The fleet specific effort distribution can explain the dome-shaped PR to otter trawls as well as the large difference in PR between the fleets. These results indicate age segregation in this cod stock, which would allow for year-class targeting by the commercial fishery. This could lead to interannual variation in PR and errors in stock assessments.
\end{abstract}

\section{Introduction}

Assessments of groundfish stocks in the Northwest Atlantic rely on age structured methods to arrive at stock abundance estimates and catch projections. An important part of the process is the estimation of the age specific exploitation pattern of the fishery, commonly referred to as partial recruitment (PR). PR has been used as an input parameter to cohort analysis (Rivard, MS 1982) or it may be estimated as part of the analysis (Pope and Shepherd, 1982; Gavaris, MS 1988). In either case, interannual variation in PR is difficult to detect and it may lead to biased estimates of important assessment parameters. Rivard and Foy (1987) found that uncertainty in PR was an important factor in errors in catch projections used to set total allowable catches. A better understanding of the dynamics of PR could improve the assessment process.

Two factors are important in determining PR, the selectivity of the fishing gear and the availability of different aged fish to the fishery (see Section 8.1, Beverton and Holt, 1957). Regulation of mesh size and hook size in commercial fisheries tends to limit the importance of selectivity changes in interannual variations in PR. However, if the fish are segregated by age, then the fishery could target large yearclasses thus making availability an important component in PR variation. The main objective in this study was to investigate whether age groups of cod (Gadus morhua) were spatially segregated and to see how this may be related to PR.
A second objective was to examine the relationships of depth and temperature with cod catch-and distribution-at-age. Several previous studies have investigated the occurrence of cod in relation to the environment. Temperature has often been cited as an important factor in controlling cod distribution (Rose and Leggett, 1988). Clark and Green (1991) demonstrated seasonal changes in temperature preference of age 3 cod in laboratory experiments. In a study of several groundfish species on the Scotian Shelf (NAFO Div. 4VWX) in summer, Scott (1982) identified preferred temperature, depth and salinity over the entire Scotian Shelf for all ages combined. Smith et al. (1991) investigated the influence of water mass characteristics on the spring distribution of age $4 \mathrm{cod}$ on the eastern Scotian Shelf and concluded that higher catches were associated with the cold intermediate layer with salinities of $32.0-33.5 \%$ and temperatures $<5^{\circ} \mathrm{C}$. Tremblay and Sinclair (MS 1985) investigated the distribution of different aged cod in the southern Gulf of St. Lawrence in autumn in relation to depth, temperature and salinity. They found that distribution varied with age, with older fish occupying deeper, more saline, and colder waters.

\section{Materials and Methods}

The cod management unit (Department of Fisheries and Oceans, Canada) on the eastern Scotian Shelf (Subdiv. 4Vs and Div. 4W) was used here as a case study (Fig. 1). The study area included several shallow banks, less than $100 \mathrm{~m}$ in depth, including 


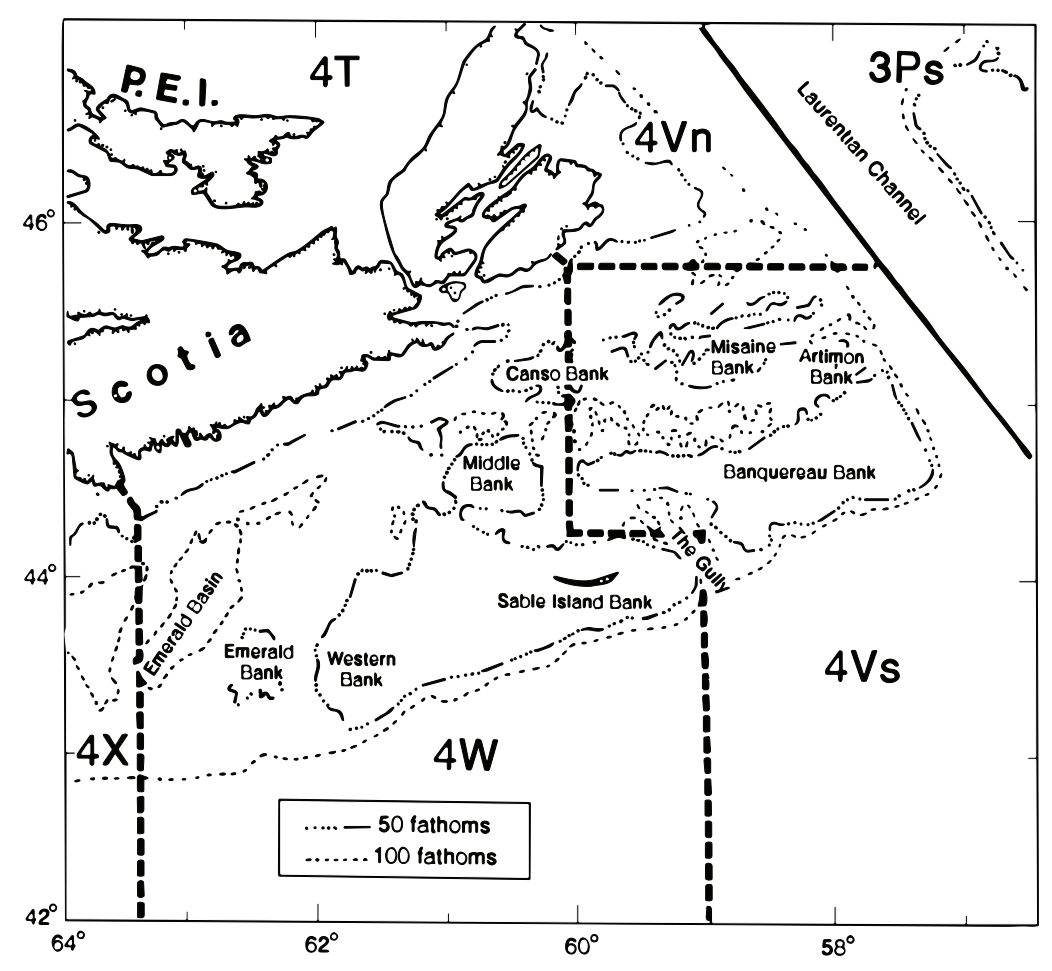

Fig. 1. Map of the eastern Scotian Shelf survey area showing NAFO Divisions.

Western, Sable Island and Emerald Banks in Div. 4W, and Banquereau and Misaine Banks in Subdiv. $4 \mathrm{Vs}$. The inshore and western parts of Div. 4W consist of a deep plateau, with depths between 100-200 $\mathrm{m}$, and the deeper Emerald Basin. Two deep channels are open to the slope waters, south of Emerald Basin and The Gully, between Sable Island Bank and Banquereau Bank.

Water on the Scotian Shelf forms three layers in summer; a warm surface layer, a cold intermediate layer, and warmer deep water (McLellan, 1954; Scott, MS 1976). Bottom temperatures are generally consistent with those in the water column. The upper $50 \mathrm{~m}$ of the water column is warm in summer and temperatures in shallow areas may exceed $10^{\circ} \mathrm{C}$. The coldest temperatures are on the banks which are in contact with the cold intermediate layer at between $50-100 \mathrm{~m}$ in depth. Deep areas of the shelf north and west of Emerald and Western Banks are bathed by relatively warm slope waters which commonly exceed $8^{\circ} \mathrm{C}$. The deeper areas of Subdiv. $4 \mathrm{Vs}$ are colder with temperatures of less than $4^{\circ} \mathrm{C}$.

Data on cod distribution were obtained from stratified random groundfish abundance surveys conducted on the Scotian Shelf during the summer between 1970 and 1989. The survey design is described by Doubleday (1981). The basic data were obtained from the Canadian Department of Fisheries and Oceans, Marine Fish Division, Biological Station, St. Andrews, New Brunswick. The surveys have been conducted by three vessels. While differences were found in fishing power among the vessels, these were not dependent on fish size (Fanning, MS 1985). Since the methods in this study involve annual percentage distributions of fish catch at depth and temperature, no correction factors were applied.

Catches-at-age of cod were calculated on a tow by tow basis according to a two stage sampling scheme described by Halliday and Koeller (1981). Catch-per-tow was adjusted to a standard tow length of $3.24 \mathrm{~km}$. Catches were weighted by the ratio of stratum area $\left(N_{h}\right)$ and the number of tows in each stratum $\left(n_{h}\right)$ on an annual basis in accordance with the stratified random sampling scheme as suggested by Smith (1990). Bottom temperature and depth of tows were also extracted from the survey database.

Cumulative frequencies of temperature and depth were used as an indication of the environmental conditions during each survey. The cumulative frequency in percent at any temperature $[F(t)]$ was calculated as represented by I. Perry and S. Smith 
(I. Perry, Department of Fisheries and Oceans, Pacific Biological Station, Nanaimo, British Columbia, pers. comm.).

$$
F_{(t)}=\frac{\sum_{h=1}^{L} \sum_{i=1}^{n h} \frac{N_{h}}{n_{h}} \Delta\left(t-Y_{i h}\right)}{\sum_{h=1}^{L} \sum_{i=1}^{n h} \frac{N_{h}}{n_{h}}} 100
$$

where $\mathrm{L}_{\mathrm{ih}} \quad \begin{aligned} & \text { number of strata } \\ & \text { observed temperature at set } \mathrm{i} \text { in } \\ & \text { stratum } \mathrm{h}\end{aligned}$
$\Delta\left(\mathrm{t}-\mathrm{Y}_{\text {ih }}\right)=\quad\left\{\begin{array}{l}\text { when }\left(\mathrm{t}-\mathrm{Y}_{\text {ih }}\right) \geq 0 \\ 0 \text { otherwise }\end{array}\right.$

The same calculation was done for depth.

The cumulative frequencies of catch in relation to either temperature or depth were calculated as an indication of the distribution of the fish in relation to these environmental variables. The following formula was used:

$$
F_{(t)}=\frac{\sum_{h=1}^{L} \sum_{i=1}^{n_{h}} \frac{N_{h}}{n_{h}} X_{i h} \Delta\left(t-Y_{i h}\right)}{\sum_{h=1}^{L} \sum_{i=1}^{n_{h}} \frac{N_{h}}{n_{h}} X_{i h}} 100
$$

where $X_{\text {in }}=$ the observed catch numbers in set $\mathrm{i}$ of stratum $\mathrm{h}$.

The median temperature or depth was defined as that corresponding to the $50 \%$ point of the cumulative frequency. The first and third quartiles were defined as the 25 and $75 \%$ points. Cumulative frequencies were calculated for ages 1 to 12 . The computer statistical package SAS was used for the calculations (Anon., 1985).

The annual percent distributions were used when calculating average conditions across years. This was done to reduce the influence of large yearclasses and catches on the results.

The cod fishery in the study area is prosecuted by vessels operating two main types of gear; otter trawls and longlines. The distribution of fishing effort by these vessels was investigated in relation to cod distribution-at-age and differences in PR to the two types of gear, using data from 1984 and 1985. Longline effort data were extracted from available fishing logs. Only vessels greater than 49.9 gross registered tons (GRT) are required to complete logs and precise information on fishing location is not always available from these. The log records selected for the analyses represented total catches of 1440 tons and 2508 tons in 1984 and 1985 , respectively, and this in turn represented 20 and $25 \%$, respectively, of the annual longline catch.
Otter trawl fishing locations were taken from the Canadian Department of Fisheries and Oceans, International Observer Program (Kulka and Waldron, 1983), where deployments are made on vessels greater than 149.9 GRT. The observed catches totalled 3996 tons and 4690 tons in 1984 and 1985, respectively. This was 10 and $11 \%$, respectively, of the total otter trawl catch in these years. It was not feasible to verify whether these data were representative of the total effort distribution of these fishing fleets and thus it was not possible to quantify the effect of effort distribution on PR. However, I considered the data to be appropriate for describing the large scale geographic distribution of fishing by the fleets. Fleet specific estimates of PR were taken from Sinclair (MS 1986).

\section{Results}

\section{Geographic distribution}

Cod were widely distributed in the study area (Fig. 2). Large catches of juvenile cod (ages 0-3) were made in Div. 4W on Middle and Sable Island Banks as well as on Emerald Bank. Catches of this age group in Subdiv. $4 \mathrm{Vs}$ were high around The Gully and on eastern Banquereau Bank. Ages 4-6, which are partially recruited to the commercial fishery, overlapped considerably with the juveniles. However, there were relatively higher catches in northern Subdiv. 4Vs in the Misaine Bank area. This shift in distribution was more apparent with older ages, and at ages 10+, catches were almost exclusively from northern Subdiv. $4 \mathrm{Vs}$.

\section{Depth distribution}

The summer research surveys are stratified by depth, and therefore the cumulative frequencies of depths sampled varied little among years. Data showed there was a distinct tendency to catch cod of older ages at increasing depths. Data for ages 1, 5 and 9 are presented for illustrative purposes (Table 1). Single large tows were noted to influence the cumulative distributions of several ages. This was due in part to the length range of the catch and also to the two staged method of estimating catch-atage. Neglecting such influences, some of the following were noted in the distributions. Median depths of age 1 distribution varied between 36 and $110 \mathrm{~m}$ with no clear temporal trend. For age 5, the medians varied between 59 and $147 \mathrm{~m}$ with evidence of a decrease in depths during the early1970s followed by relatively stable distributions in the early-1980s. The values for 1986-88 were among the highest in the series followed by a low value in 1989. At age 9 the medians varied between 75 and $159 \mathrm{~m}$. A trend in decreasing depths was noted from a maximum in 1977-78 to a minimum in 1984. The values for the last 5 years were relatively high and stable. 


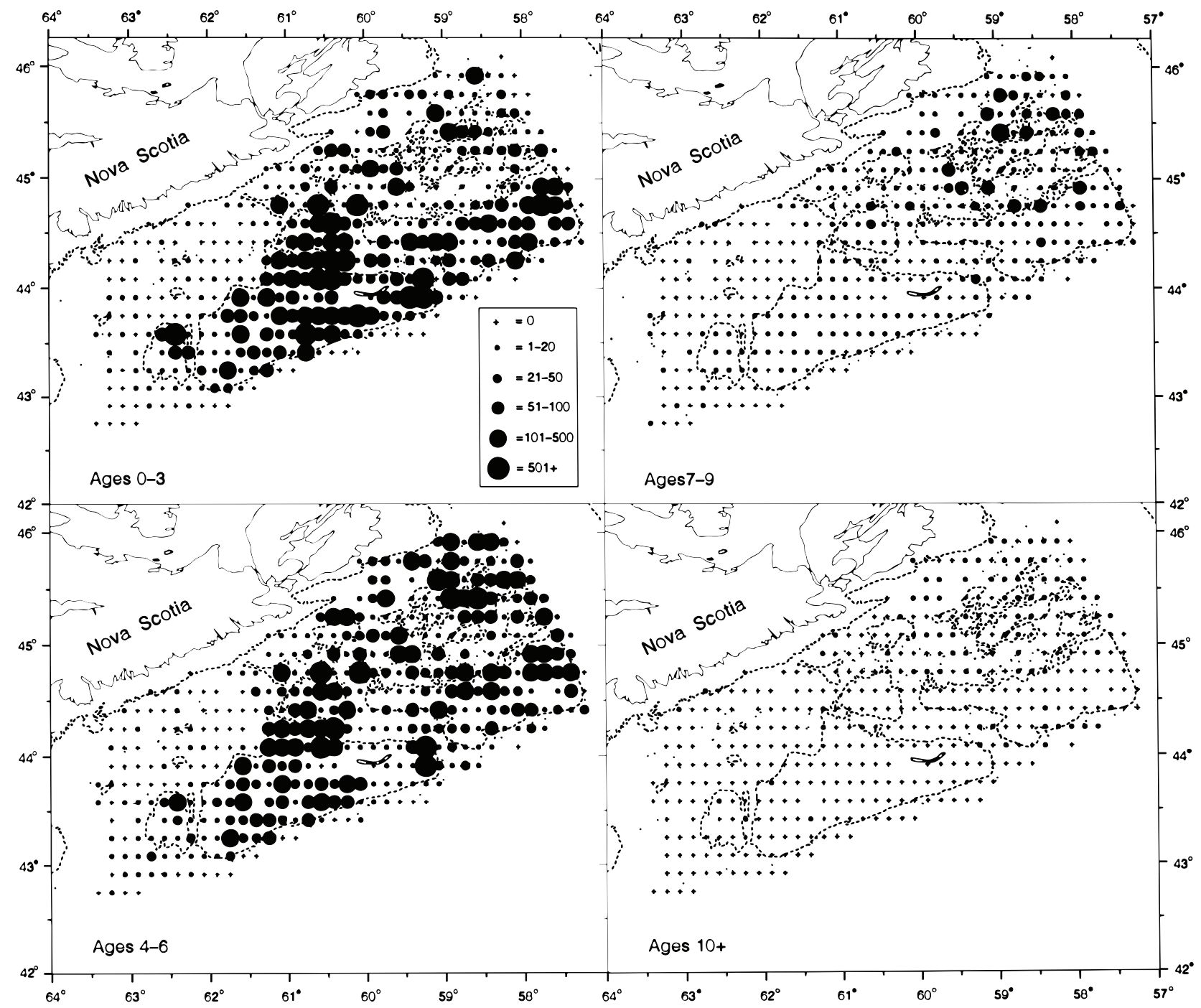

Fig. 2. Catches (numbers) of different age groups of cod from eastern Scotian Shelf summer groundfish surveys $1970-$ 89. Catches were aggregated by $10^{\prime}$ of latitude and longitude.

Cumulative catch distributions at depth were calculated for each age group across all years. The curves for ages 1, 5 and 9 indicated age-specific differences in the distribution of cod by depth (Fig. 3). As noted above, the older cod were distributed deeper. The percentages of the catches in $50 \mathrm{~m}$ depth intervals given in Table 2 shows the availability of different age groups varied considerably with the depth fished.

The medians and quartiles of distributions by depth for all ages over the entire time series indicated an increasing trend in depth with age (Fig. 4). The median depths-at-age were both greater than and less than those sampled ("Obs" on the $\mathrm{x}$-axis) thus emphasizing the apparent age-dependent shift in distribution with depth.

\section{Temperature distribution}

Median observed bottom temperatures were always greater in Div. 4W than in Subdiv. 4Vs, ranging between $5^{\circ}$ to $9^{\circ} \mathrm{C}$ in the former and between $1^{\circ}$ to $4^{\circ} \mathrm{C}$ in the latter (Fig. 5). While the time series was variable in Div. $4 \mathrm{~W}$, an increasing trend was evident between 1970-86, except for 2 cold years in 1982 and 1983. The median temperatures in the last 3 years were among the lowest observed. Median temperatures in Subdiv. 4Vs were relatively stable over the time period.

The cumulative catch distributions for ages 1, 5 and 9 indicated that age 1 fish are found, on average, at warmer temperatures than older fish (Fig. 6). However, there was essentially no difference in the 
TABLE 1. Annual median depth and temperature at which age 1,5 and 9 cod were captured on the eastern Scotian Shelf.

\begin{tabular}{|c|c|c|c|c|c|c|}
\hline \multirow[b]{2}{*}{ Year } & \multicolumn{3}{|c|}{ Depth (m) } & \multicolumn{3}{|c|}{ Temperature $\left({ }^{\circ} \mathrm{C}\right)$} \\
\hline & Age 1 & Age 5 & Age 9 & Age 1 & Age 5 & Age $S$ \\
\hline 1970 & 91 & 120 & 109 & 4.3 & 2.6 & 6.3 \\
\hline 1971 & 106 & 135 & 106 & 3.4 & 2.5 & 3.4 \\
\hline 1972 & 43 & 117 & 156 & 5.6 & 1.3 & 3.7 \\
\hline 1973 & 36 & 110 & 110 & 6.0 & 3.7 & 3.7 \\
\hline 1974 & 55 & 101 & 101 & 4.1 & 2.1 & 2.0 \\
\hline 1975 & 55 & 83 & 113 & 4.3 & 3.2 & 1.1 \\
\hline 1976 & 59 & 88 & * & 3.3 & 2.2 & * \\
\hline 1977 & 55 & 142 & 156 & 5.3 & 3.6 & 3.8 \\
\hline 1978 & 105 & 108 & 159 & 4.3 & 3.5 & 2.0 \\
\hline 1979 & 71 & 59 & 143 & 7.3 & 5.1 & 3.4 \\
\hline 1980 & 70 & 70 & 135 & 6.7 & 3.8 & 3.8 \\
\hline 1981 & 46 & 107 & 118 & 11.8 & 3.2 & 3.2 \\
\hline 1982 & 92 & 65 & 134 & 5.3 & 2.5 & 1.6 \\
\hline 1983 & 39 & 78 & 109 & 8.4 & 3.6 & 2.2 \\
\hline 1984 & 110 & 75 & 75 & 3.1 & 2.6 & 2.5 \\
\hline 1985 & 71 & 77 & 149 & $\star *$ & $\star *$ & $\star *$ \\
\hline 1986 & 38 & 147 & 148 & 6.7 & 2.9 & 2.7 \\
\hline 1987 & 50 & 137 & 137 & 5.0 & 1.3 & 1.3 \\
\hline 1988 & 45 & 134 & 134 & 5.6 & 2.7 & 2.7 \\
\hline 1989 & 73 & 67 & 146 & 2.9 & 2.2 & 0.8 \\
\hline
\end{tabular}

* No age 9 cod were caught in the 1976 survey.

** Temperature data not available.

distributions of ages 5 and 9 with respect to temperature. Approximately $80 \%$ of the curve for adult fish was at temperatures less than $4^{\circ} \mathrm{C}$, while about $35 \%$ was in the same temperature range for age 1.

Median temperatures were highest $\left(5^{\circ} \mathrm{C}\right)$ at age 1 (Fig. 7). These decreased with age until age 5 after which they were relatively stable between $2.5^{\circ}$ to $3.0^{\circ} \mathrm{C}$. The temperature distributions-at-age were narrower than the range sampled suggesting that the former was not an artifact of the general environmental conditions in the study area.

The annual median temperatures for the distribution of ages 5 and 9 showed no temporal trend

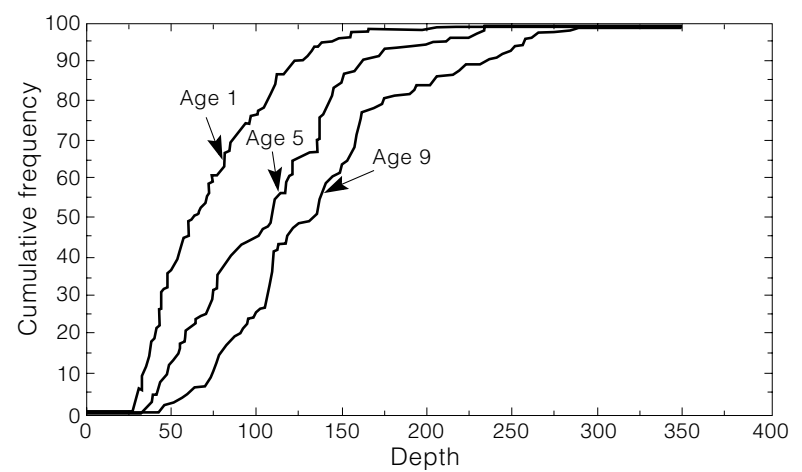

Fig. 3. Cumulative frequency distribution of catches at depth for age 1, 5 and 9 cod in Subdiv. 4Vs and Div. 4W, 1970-89. and varied little (Table 1). At age 1 the annual values were higher and stable from 1970 to 1978, increased to a maximum in 1981, and declined to 1989.

Bottom temperatures were several degrees warmer at the same depth in Div. $4 \mathrm{~W}$ than in Subdiv. $4 \mathrm{Vs}$ (Fig. 8). The median depths- and temperatures-at-age of cod catches from research vessel surveys were also included in this figure. The catches at young ages (1-3) were between the temperatures at similar depths in the two areas. However, at older ages the median temperatures of capture were much closer to those observed in Subdiv. 4Vs.

\section{Fishery distribution and PR}

PR was quite different for the two gears (Fig. 9). Otter trawl PR was dome-shaped with full recruitment at ages 6 and 7 . Longline PR was more flattopped with full recruitment at age $9+$. Longline and

TABLE 2. Percent distribution of cod catches by $50 \mathrm{~m}$ depth zones.

\begin{tabular}{crcc}
\hline \hline Depth zone $(\mathrm{m})$ & Age 1 & Age 5 & Age 9 \\
\hline 0 to 50 & 37 & 12 & 4 \\
50 to 100 & 41 & 34 & 23 \\
100 to 150 & 20 & 41 & 36 \\
150 to 200 & 2 & 7 & 22 \\
$200+$ & 0 & 6 & 15 \\
\hline
\end{tabular}




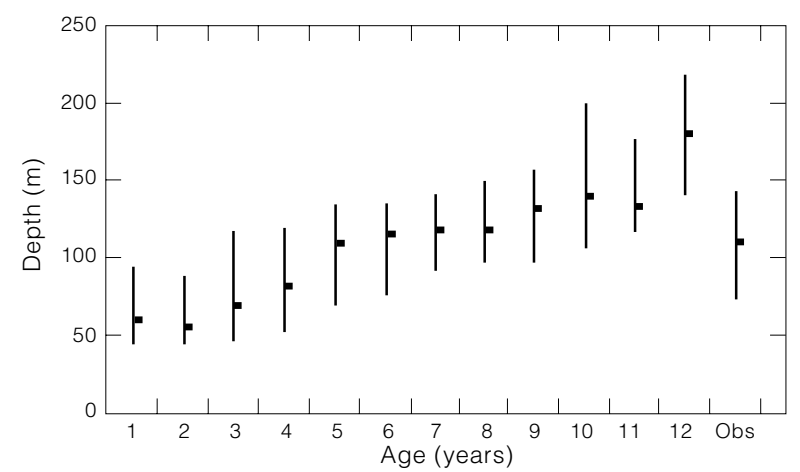

Fig. 4. Medians and quartiles of catch-at-age by depth of Subdiv. 4Vs and Div. 4W cod, 1970-89. The last vertical line (Obs) represents the distribution of sampled depths.

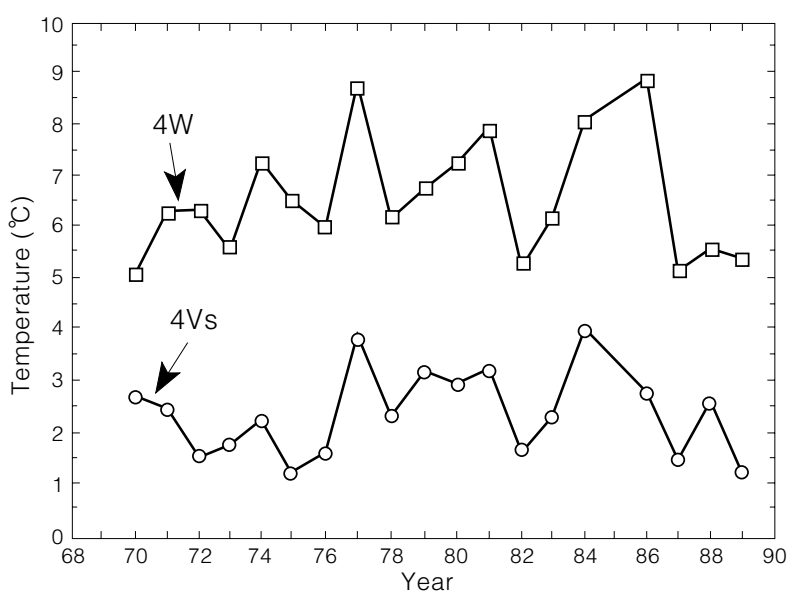

Fig. 5. Median bottom temperatures observed in Subdiv. $4 \mathrm{Vs}$ and Div. 4W during summer groundfish surveys.

otter trawl fishing effort distributions were distinct in the study area (Fig. 10). Otter trawl effort was concentrated on the relatively shallow banks, and in particular on Banquereau and Sable Island Banks. Little effort was expended in the northern part of Subdiv. 4Vs. Longline effort was predominantly in the deeper waters north of Banquereau Bank with little effort on the shallow banks.

\section{Discussion}

This study demonstrates age segregation of cod in Subdiv. 4Vs and Div. 4W. Research vessel survey catches of young cod (ages 0-3) came predominantly from the shallow Sable Island, Middle, Banquereau, and Misaine Banks (Fig. 2). A shift in distribution with increasing age toward the northeast was evident, and there was a concurrent shift in distribution toward greater depths (Fig. 3 and 4). This study was focused on data from the summer

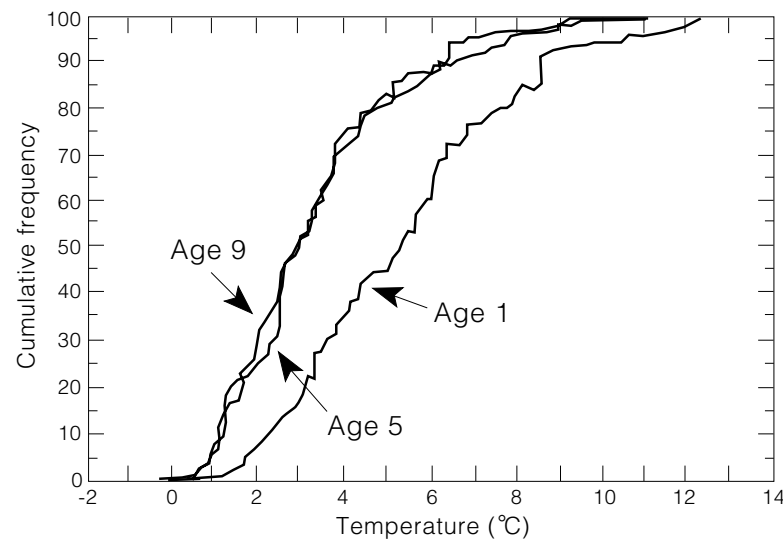

Fig. 6. Cumulative frequency distribution of catches of age 1,5 and 9 cod at temperature in Subdiv. $4 \mathrm{Vs}$ and Div. 4W, 1970-89.

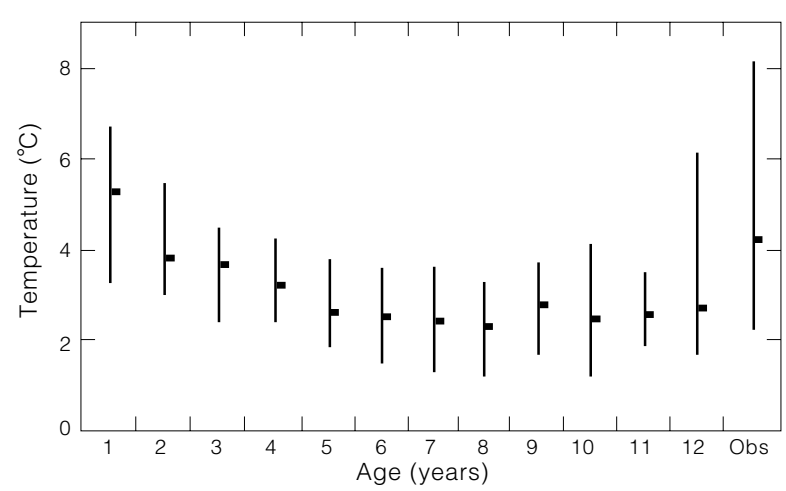

Fig. 7. Median and quartiles of catch-at-age of cod by temperature in Subdiv. 4Vs and Div. 4W, 197089. The last vertical line (Obs) represents the distribution of sampled temperatures.

research vessel surveys. Although not presented here, preliminary analysis of spring and autumn survey results indicate a similar trend for older fish to be caught in deeper waters (Sinclair and Smith, MS 1987).

Changes in gear selection with depth may explain part of the apparent segregation of the ages. Engås and Godø (1989) have reported size dependent selectivity changes of research trawls in relation to trawl sweep lengths for Northeast Arctic cod. Proportionately more large cod $(>40 \mathrm{~cm})$ were caught with trawls equipped with longer sweep lines. The authors suggest that this is due to large fish being more sensitive than small fish to the herding effect of the doors and sand clouds generated by the sweeps. It has been noted on Canadian groundfish surveys that the door spread increases with depth if the same warp/depth ratio is used while fishing (P. Koeller, Department of Fisheries 


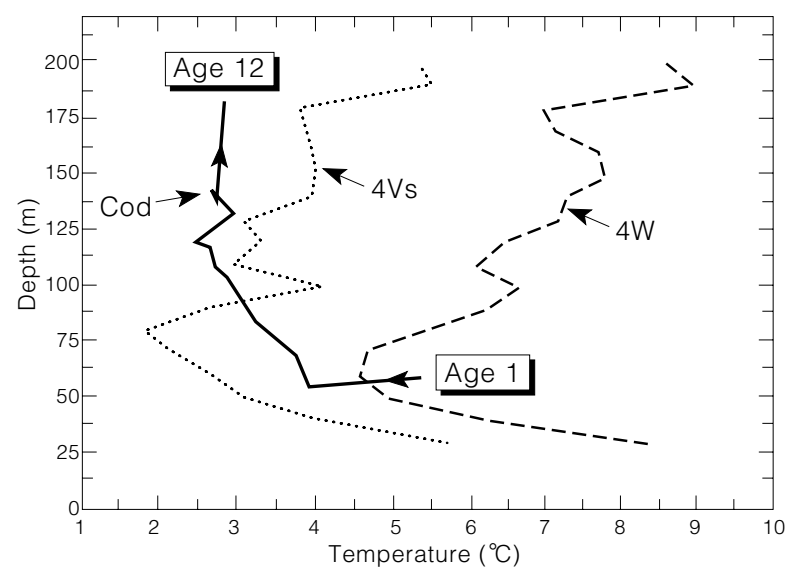

Fig. 8. Median bottom temperatures by area and depth in Subdiv. 4Vs and Div. 4W for the period 197089 compared to median depth- and temperatureat-age of cod.

and Oceans, Bedford Institute of Oceanography, Dartmouth, Nova Scotia, pers. comm.). While the sweep lengths remain constant, the sweep angles would increase the sand clouds. This, together with an increase of door spread, could increase the capture of large fish.

While the gear selection effect may contribute to the apparent change in distribution, the contention from this study is that it can only be considered to be a minor contribution. Here the mean catchper-tow at age by depth intervals of $50 \mathrm{~m}$ for the entire summer survey series was calculated (Table 3 ). The ratios for the young fish were several orders of magnitude greater than what could be explained by gear selection alone, based on the data reported by Engås and Godø (1989).

The distribution of juvenile catches reported here supports the conclusion of McKenzie (1956), that several stock components occupy the Subdiv. 4Vs and Div. 4W area. Several nursery areas were evident, on Middle Bank, Sable Island Bank both south and east of Sable Island, as well as on Banquereau Bank. However, the adult distribution appeared to be more homogeneous suggesting considerable mixing of older fish. Without more recent stock identification information, the origins of these older fish was not clear.

It may be premature to draw firm conclusions about whether depth or temperature preferences of cod, or some other related variable such as prey distribution, can explain the observed patterns in distribution. There is little information on the underlying behavioral and physiological processes at work. While temperature is often cited as an important factor in determining cod distribution, this is

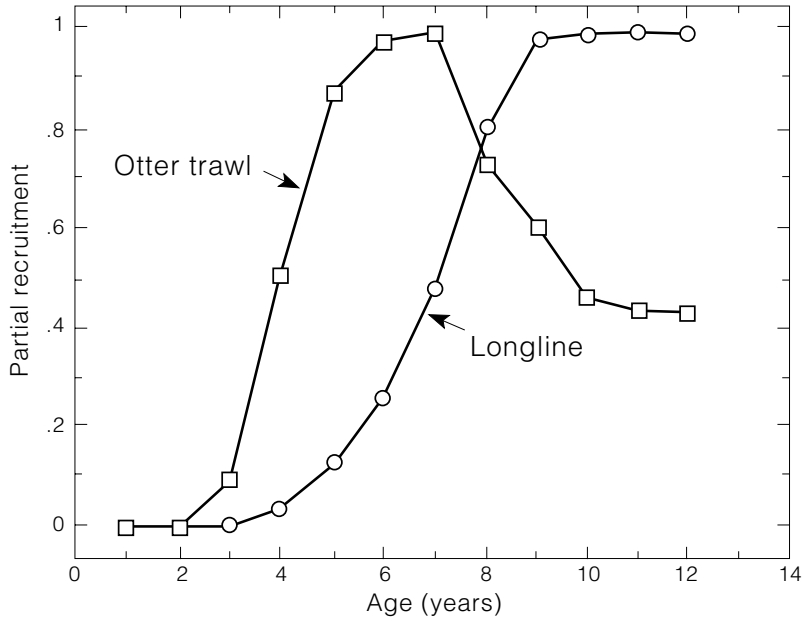

Fig. 9. Partial recruitment estimates for longline and otter trawl fisheries of Subdiv. 4Vs and Div. 4W cod in 1982-84. (From Sinclair, MS 1986).

largely based on observation rather than experimentation. The results in this study indicate that cod are not found ubiquitously with respect to temperature, but that they occur at the lower end of the observed temperature range. However, this is confounded by the tendency of older fish to move to deeper, colder waters.

Nevertheless, a comparison of catches with respect to temperature and depth in Subdiv. 4Vs and Div. 4W suggests that cod are more selective of temperature than depth. Median depths of capture of age 1-4 cod increased from $55 \mathrm{~m}$ to $83 \mathrm{~m}$. Median temperatures of capture for the same ages declined from $5.3^{\circ}$ to $3.3^{\circ} \mathrm{C}$. Bottom temperatures at these depths in both Subdiv. 4Vs and Div. 4W were close to the median temperatures at which these ages were caught (Fig. 8). For ages 5+ the median temperatures of capture were consistently between $2^{\circ}$ to $3^{\circ} \mathrm{C}$ with no apparent trend while the median depths of capture increased. Temperatures in Subdiv. 4Vs at depths greater than $100 \mathrm{~m}$ were in this range but bottom temperatures increased with depth in Div. $4 \mathrm{~W}$ to values above $6^{\circ} \mathrm{C}$. Very few cod were caught in the deep areas of Div. 4W (Fig. 2). Thus it may be interpreted that older cod avoid these warmer temperatures and consequently move toward Subdiv. 4Vs as they descend to greater depths.

The temperature distribution of cod is important for the commercial fishery and in the design of research surveys for fish abundance. Over $80 \%$ of commercial sized cod (age 5+) were taken at temperatures less than $5^{\circ} \mathrm{C}$. Fishing for cod in waters warmer than this may not be as successful as in areas with colder temperatures. Smith et al. (1991) have indicated the importance of considering water 


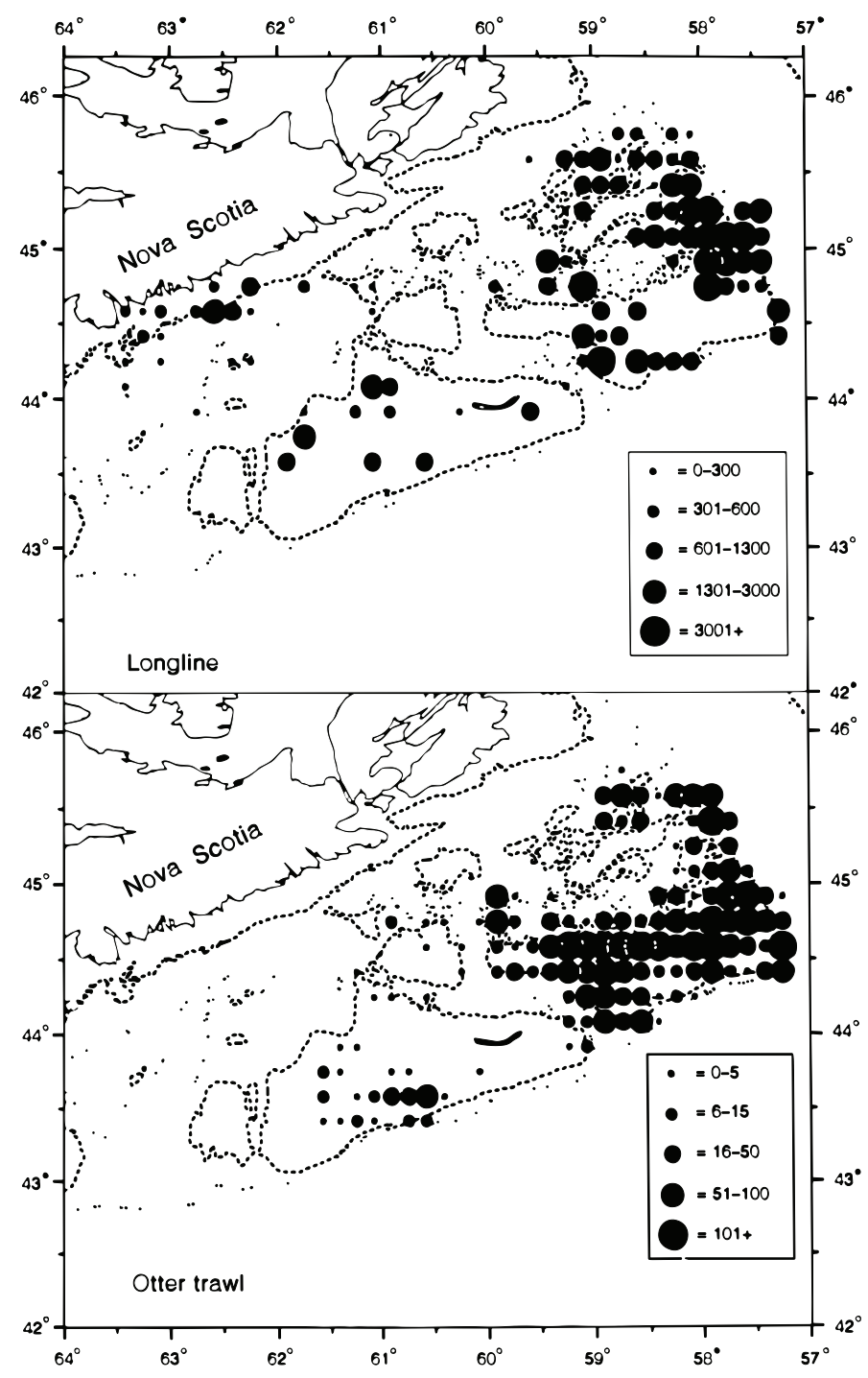

Fig. 10. Fishing effort distribution in 1984 and 1985 for longlines and otter trawls. Effort units are numbers of lines for longlines, and hours fished for otter trawls. Effort was aggregated by 10 ' of latitude and longitude.

temperature as well as other characteristics of water masses in interpreting the results of abundance surveys. These results support their conclusions.

The distribution of fishing effort by the two main gear components of the cod fishery in the study area along with the differences in distribution of cod-at-age may explain the differences in PR among the fleets. The dome-shaped PR for otter trawls observed here was not consistent with other trawl mesh selection studies, which usually indicate asymptotic selection as a function of size. Given the concentration of otter trawl fishing on shallow banks where the youngest fish are found, it is likely that the decline in PR for older ages is a result of the low availability of older fish in the areas fished. Selection data were sparse for longlines as was information on the hook size used. However, it was possible that the longlines tended to select older fish than otter trawls. It is unlikely, however, that selection alone could explain the large difference in PR of the two gears. The higher availability of older fish in the areas fished with longlines is likely to be more important in explaining the higher age of full recruitment to this gear.

The age segregation of cod has important implications in the interpretation of fisheries statistics. A shift of the commercial fishery to shallower waters and toward the south and west of the management 
TABLE 3. Mean catch-per-standard-tow (numbers) of cod-atage by $50 \mathrm{~m}$ depth intervals.

\begin{tabular}{|c|c|c|c|c|c|}
\hline \multirow[b]{3}{*}{ No. of tows: } & \multicolumn{5}{|c|}{ Depth zone (m) } \\
\hline & $<50$ & $50-100$ & $100-150$ & $150-200$ & $>200$ \\
\hline & 148 & 649 & 380 & 190 & 323 \\
\hline \multicolumn{6}{|l|}{ Age } \\
\hline 0 & 0.053 & 0.134 & 0.063 & 0.000 & 0.007 \\
\hline 1 & 13.644 & 1.428 & 0.564 & 0.168 & 0.024 \\
\hline 2 & 81.623 & 8.111 & 3.553 & 0.703 & 0.199 \\
\hline 3 & 83.940 & 9.701 & 6.912 & 1.996 & 0.903 \\
\hline 4 & 31.173 & 7.722 & 6.859 & 2.070 & 1.168 \\
\hline 5 & 9.277 & 5.002 & 3.826 & 2.250 & 1.852 \\
\hline 6 & 3.224 & 2.420 & 1.869 & 1.823 & 1.509 \\
\hline 7 & 0.906 & 1.132 & 0.978 & 1.250 & 1.009 \\
\hline 8 & 0.254 & 0.290 & 0.393 & 0.596 & 0.611 \\
\hline 9 & 0.063 & 0.125 & 0.124 & 0.230 & 0.230 \\
\hline 10 & 0.008 & 0.029 & 0.081 & 0.133 & 0.138 \\
\hline 11 & 0.001 & 0.022 & 0.048 & 0.044 & 0.071 \\
\hline 12 & 0.001 & 0.004 & 0.009 & 0.030 & 0.036 \\
\hline
\end{tabular}

unit would result in an increase in the availability of younger age groups to fishing effort. The opposite effect would occur for older age groups if effort shifted toward deeper water and toward the north and east. Fishermen could follow strong yearclasses and thus PR could vary annually. Such a tendency could bias trends in catch-per-unit-effort at age used to calibrate Sequential Population Analyses in stock assessments as well as parameters used in catch projections. Closer attention to the distribution of fishing effort is warranted in stock assessments.

\section{Acknowledgements}

I thank the staff of the Marine Fish Division, St. Andrews Biological Station and Bedford Institute of Oceanography who have been involved in the collecting, editing and analysis of the research vessel cruise data that made this study possible. In particular I thank J. Gale and C. Annand for their help in assembling the data and L. Ingles who helped assemble the longline logbook data. I also thank M. Castonguay, D. D'Amours and two anonymous referees for their helpful comments on the manuscript.

\section{References}

ANON. 1985. SAS user's guide: statistics, version 5 Edition. SAS Institute Inc., Cary, N.C., USA.

BEVERTON, R. J. H., and S. J. HOLT. 1957. On the population dynamics of exploited fish populations, $\mathrm{H}$. M. Stationary Office, London. Fish. Invest. Lond., Ser. 2, 19: $533 \mathrm{p}$.

CLARK, D. S., and J. M. GREEN. 1991. Seasonal variation in temperature preference of juvenile Atlantic cod (Gadus morhua), with evidence supporting an energetic basis for their diel vertical migration. Can. J.
Zool., 69: 1302-1307.

DOUBLEDAY, W. G. 1981. Manual on groundfish surveys in the Northwest Atlantic. NAFO Sci. Coun. Studies, 2: $55 \mathrm{p}$.

ENGÅS, A., and O. R. GØDO. 1989. The effect of different sweep lengths on the length composition of bottomsampling trawl catches. ICES J. Cons., 45: 263-268.

FANNING, L. P. MS 1985. Intercalibration of research vessel survey results obtained by different vessels. CAFSAC Res. Doc., No. 3, 43 p.

GAVARIS, S. MS 1988. An adaptive framework for the estimation of population size. CAFSAC Res. Doc., No. 29, 12 p.

HALLIDAY, R. G., and P. A. KOELLER. 1981. A history of Canadian groundfish trawling surveys and data usage in ICNAF Divisions 4TVWX. In: Bottom trawl surveys W. G. Doubleday and D. Rivard (eds.). Can. Spec. Pub. Fish. Aquat. Sci., 58: 27-41.

KULKA, D. W., and D. WALDRON. 1983. Atlantic observer programs - a discussion of sampling from commercial catches at sea. In: Sampling catches of marine fish and invertebrates W. G. Doubleday and D. Rivard (eds.) . Can. Spec. Pub. Fish. Aquat. Sci., 66: 255-262.

McKENZIE, R. A. 1956. Atlantic cod tagging off the southern Canadian mainland. Bull. Can. Fish. Res. Board, 105: $93 \mathrm{p}$.

McLELLAN, H. J. 1954. Bottom temperatures on the Scotian Shelf. J. Fish. Res. Board Can., 11: 404-418.

POPE, J. G., and J. F. SHEPHERD. 1982. A simple method for the consistent interpretation of catch-at-age data. ICES J. Cons., 40: 176-184.

RIVARD, D. MS 1982. APL programs for stock assessments (revised). Can. Tech. Rep. Fish. Aquat. Sci., 1091: $146 \mathrm{p}$.

RIVARD, D., and M. G. FOY. 1987. An analysis of errors in catch projections for Canadian Atlantic fish stocks. Can. J. Fish. Aquat. Sci., 44: 967-981.

ROSE, G. A., and W. C. LEGGETT. 1988. Atmosphereocean coupling and Atlantic cod migrations: effects of wind-forced variations in sea surface temperatures 
and currents on nearshore distributions and catch rates of Gadus morhua. Can. J. Fish and Aquat. Sci., 45: 1234-1243.

SCOTT, J. S. 1976. Summer distribution of groundfish on the Scotian Shelf 1970-74. Can. Tech. Rep. Fish. Aquat. Sci., 635: $51 \mathrm{p}$.

1982. Depth, temperature and salinity preferences of common fishes of the Scotian Shelf. J. Northw. Atl. Fish. Sci., 3: 29-39.

SINCLAIR, A. MS 1986. Longliner - otter trawler interactions in cod fisheries on the Scotian Shelf: implications of differences in partial recruitment. CAFSAC Res. Doc., No. 94, 27 p.
SINCLAIR, A., and S. J. SMITH. MS 1987. Assessment of 4VsW cod. CAFSAC Res. Doc., No. 72, 62 p.

SMITH, S. J. 1990. Use of statistical models for the estimation of abundance from groundfish trawl survey data. Can. J. Fish. Aquat. Sci., 47: 894-903.

SMITH, S. J., R. I. PERRY, and L. P. FANNING. 1991. Relationships between water mass characteristics and estimates of fish population abundance from trawl surveys. Environ. Moni. Assess., 17: 227-245.

TREMBLAY, M. J., and M. SINCLAIR. MS 1985. Gulf of St. Lawrence cod: age specific geographic distributions and environmental occurrences from 1971 to 1981. Can. Tech. Rep. Fish. Aquat. Sci., 1387: 43 p. 